\title{
Using Design Activism to Empower and Value a Community Group
}

\author{
INGE ANDREW
}

\begin{abstract}
I have been working as a Masters student with a group of people that don't generally have a voice in everyday discourse - perpetrators of domestic violence. Stopping Violence Dunedin (SVD) is run by experienced facilitators who instead of placing blame on their clients, work to empower them with a sense of community and positive self-worth. These men are taught to appreciate and build on their own sense of worth and my Masters project focused on creating a value object to enhance their journey of change towards a non-violent life. The value creation process involved using communication design as a tool to develop a social enquiry, working to understand this community and the challenges they face. By looking at their entire system of interactions and experiences, I was able to develop a series of milestones for the men which led to the development of a key prototype. The first 'shift' key could be gifted to the men in the group who show a shift in their thinking and are able to engage in the process of change. The second 'manhole cover' key to the men who develop leaderships skills and can mentor newer group members. The outcome of the object created a value proposition working to celebrate the milestones that these men reach. This sense of value and appreciation could also extend to the possibility of an alternative future for the men - a future without violence.
\end{abstract}

KEYWORDS: Design Activism; Value Creation; Inclusive Design; Design Theory; Communication Design

\section{Introduction}

Otago Polytechnic (OP) in Dunedin, Aotearoa / New Zealand is a place of learning that lives and breathes by its vision and values as well as its commitment to upholding the commitments to the Treaty of Waitangi / Te Tiriti o Waitangi ${ }^{1}$. OP's vision is 'Our people make a better world' 'Kia tū ki te tahi' and our values are caring (manaakitaka), courage (māia), accountability (takohaka) and empowerment (whakamanataka). Manaakitaka in particular is a strong value at OP where hospitality and care are considered as reciprocal, ensuring that value is both given and received. The School of Design also commit to sustainable teaching by developing a sense of social responsibility in the students it teaches. I started my learning journey at OP in 2016 when I enrolled in a Graduate Diploma in Design (Communication) which was followed by a Masters of Design. As a Higher Polytechnical Educational (HPE) institution, OP installed in me 
the value of practice-based research (leading me to understand and build the context of my masters), followed by practiced-led research where the benefit of the project became the making of a 'value object' for a community group. The core commitment of this project was to develop an inclusive design inquiry, using design activist methodologies and feminist theory to understand the journey of transformation that men at Stopping Violence Dunedin (SVD) must go through in order to change the trajectory of their lives. In working with a communitybased group, I was given the opportunity to explore experiences and interactions which resulted in developing a number of client milestones which could then be celebrated on achievement. This project followed a qualitative design methodology but went a step further by contextualising the concept of value in both my learning process as well as in the final outcome for the men at SVD.

\section{Understanding Perpetrators of Domestic Violence}

Family violence is a complicated social issue and the statistics for domestic violence are high in Aotearoa, particularly for our tangata whenua (Māori - the indigenous people of New Zealand / Aotearoa). Research into violent perpetrators and their rationalisations is relatively recent and there are a diverse range of theories on the issue. Primary preventative measures, long-term investment and the need to develop a holistic approach that incorporates support from more than just the justice system (e.g. mental health services, financial and employment help) is considered critical (Polaschek, 2016). It is well referenced that perpetrators of domestic violence are often victims themselves, having experienced domestic, sexual abuse or other types of trauma in their own lives (Baker, 2013; Campbell, 2012; Roguski \& Gregory, 2014; Snegirev, 2017). It is also understood however that not all abused children grow up to be violent.

There are several Stopping Violence Centers throughout New Zealand / Aotearoa but SVD specifically works to support the individuals in their care by looking past the label of 'violent perpetrator' and building trust and connections within group sessions so that the men can tell their own personal story, often for the first time. This research was instigated in a slightly unusual situation where I approached SVD to see if I could work with them (they didn't approach me with a design problem). I initially wanted to see if I could use communication design to transform public views of violent perpetrators, many believing that they should be incarcerated forever. SVD challenges embedded societal notions that these men are not redeemable by offering individual and group therapy which offer positive change. The manager of SVD Cinnamon Boreham said in an initial interview with me that some of the SVD clients have experienced unbelievable trauma and when they enter the group situation and it's often the first time that anyone has asked them "what happened to you?". The community that develops at SVD gives the members a sense of belonging and hope, especially as they try and navigate the often stressful outside world without using violence as a first response. This support system is a strong presence at SVD. When discussing this project early in 2019, Boreham said that she would like to be able to extend the support network to the men during the week in some way. In her own research, Boreham discusses the importance of this support system, quoting a client, "when I feel like I'm going to lose my shit the bloody group comes into my head. I don't want to let the guys down" $(2018, p .15)$. In order to develop some understanding of the men who are part of SVD, my goal shifted from wanting to create public comment to using design methodologies to develop an understanding of their process of change. I also wanted 
to create value for the men by finding a design intervention point and creating a value object which might help them in their journey.

\section{Design Activism Methodologies}

My own academic research on violent perpetrators was combined with design activism methodologies and how critical theory can be applied to both interpret and reflect on design in practice. I view design activism as similar to Hirsh's idea of disruption design where the act of interruption allows a space for questioning assumptions around a community of people that are often disregarded (Hirsh, 2009). Feminist theory and specifically intersectionality and its commitment to social justice is also a useful lens to apply, even to male perpetrators of domestic violence. MacDowell (2013) also applied intersectionality to the identities of both victims and perpetrators of domestic violence. She outlined that perpetrators are often shaped by stereotypes of race, gender, class, sexuality and ethnicity. We can all experience intersectional complexity.

My exploration also incorporated a search for narratives in the forms of quotes from former perpetrators of domestic violence, sourced from academic papers, conversations, podcasts etc. These were instrumental in developing some understanding of perpetrators and the idea of a possible transformation to a life without violence. Narratives like these can be used as a tool to understand each other as well as reflect on our own identities (Grimaldi, Silvia; Fokkinga, Steven; Ocnarescu, 2013). A salient example can be seen from Roguski and Gregory's research who interviewed former violent perpetrators to understand their motivations for change. An interviewee talked about telling the truth to a group of men. "My turning point was telling my story. That was a big eye opener for me. Telling the class what I did" (2014, p.34). Boreham (2018) and other researchers (Manning et al., 2017; Roguski \& Gregory, 2014; Ruwhiu et al., 2009) talk about the journey of transformation that men go on, the length of which differs from individual to individual. This journey can culminate in a raising of consciousness where men begin to realise that their violent actions have long ranging consequences to the people around them but that there is also the possibility of hope and change. The journey of change was an interesting concept from a design perspective and offered an opportunity to apply creative research practices to explore a design intervention point.

Thematic content analysis of interviews with four experienced SVD facilitators revealed seven common themes for the men who undertake the journey of change. These themes were also validated by other research (Baker, 2013; Pihama et al., 2019; Polaschek, 2016; Roguski \& Gregory, 2014; Ruwhiu et al., 2009). The seven themes are as follows:

1) Men share, listen and tell stories.

2) The group process helps to develop/build authentic relationships and connections.

3) Children are an important motivation for change.

4) Mentors (those who have attended SVD for some time) offer model behaviour and hope for the new men.

5) The men develop self-awareness which in turn raises consciousness.

6) Cultural connectiveness is important to support positive transformation.

7) There is an overall journey of transformation that is witnessed by both facilitators and the men themselves.

The telling of stories and building connections are also important elements of any investigation that is seeking to ensure that the result of any design outcome is an active motivation or 
even change in behaviour for the user. Thorpe (2011) described the basic criteria of design activism which included revealing or framing an issue as well as ensuring that any design outcome has either a reformative or transformative experience. In this case design and transformation can also be identified with the concept of an alternative future where the men at SVD are given an opportunity to believe that change is possible but also that a future without violence is feasible.

In order to interpret the identified themes further, I developed a version of journey mapping for the SVD men utilitisng the concept of the Hero's Journey ${ }^{2}$. This ubiquitous concept of the circular journey, where the hero gets a call to adventure, initially refuses the call but with the help of a sidekick (or mentor) embarks on a journey of tests and rewards, resulting in a homecoming with a hero's story (Lupton, 2017). This relates too to the themes above around the men's journey of transformation and the importance of mentors in the process of change (those that have 'been there done that'). This investigation resulted in a design intervention point where the so-called hero goes through trials and failures after he crosses the threshold of the initial parts of the journey. It makes sense too that men who commit to making a change will go through phases of 'one step forward and two steps back'. The initial research and identification of themes also initiated drawings of ideas associated with journey and change, resulting in a specific pathway of support for the SVD men (figure 1).

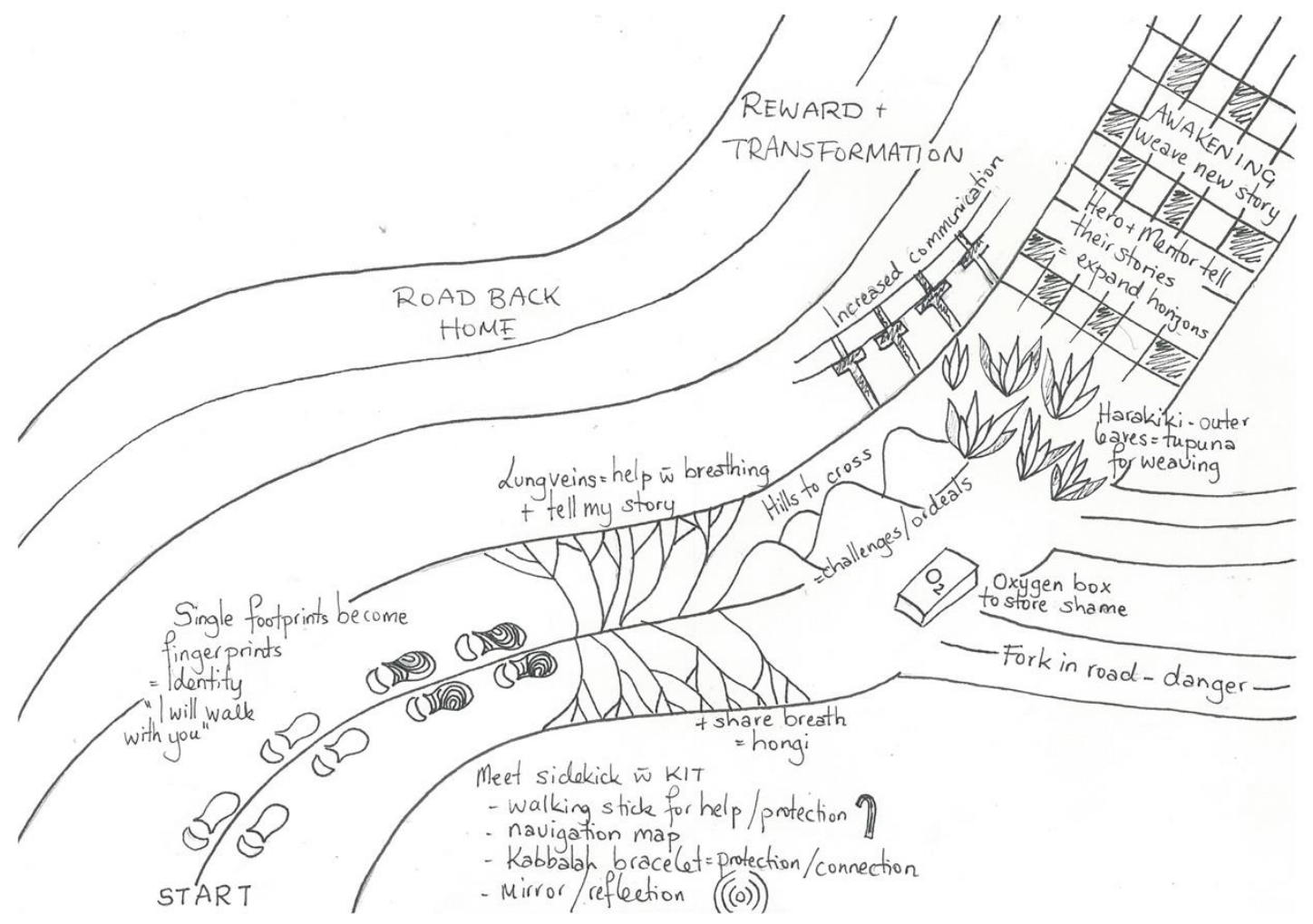

Figure 1 - Pathway of Support for Stopping Violence Dunedin (SVD) 
This as well as further research and reflection culminated in a series of milestones which were agreed on by the SVD facilitators:

1) Enter the door of SVD.

2) Return to SVD.

3) Tell your story.

4) Make connections with peers.

5) See your story from other perspectives (raise consciousness).

6) Take threads of other stories that apply to you.

7) Accept hope/transformation.

Two further milestones were added by two SVD men who attended a focus group:

8) Vulnerability.

9) Identify (identifying your own key issues).

\section{Identifying a Value Object}

Now armed with knowledge of the process, I set about considering a value object that the men could carry with them as a reminder of both the journey of transformation and the support from their peers. I thought about what men carry in their pockets - a wallet, cellphone, and keys. The key is a useful metaphor for a journey of change but also carries many other meanings like opening and closing doors, new beginnings, unlocking potential etc. During a discussion with the SVD facilitators, the idea of the key was attractive but, in their opinion, not every group member should be given a gift of this kind as some don't fully engage with the process (some only attend SVD to fulfill a court order). They also thought that seven milestone keys were too many and it would be difficult to pinpoint when those milestones might be reached. Boreham felt that a key would be better presented when the facilitators see a 'shift' in a group member. According to the group this engagement with the SVD process, where a raising of consciousness and an understanding of the consequences of violent behaviour, usually happens around the $4-6$ week mark. Boreham also suggested that a second key could be presented to the men who become mentors. This is currently a casual process at SVD but is a considerable achievement when men in the groups start to show leadership. The facilitators also agreed that the key could also be a healthy source of competition between the men.

Once the value object was determined, the process could begin on the design and making of the key which included a tactile pattern with the achieved milestone. The pattern on the key was relevant as both a memory enabler and a reminder of the milestones that the user had achieved as well as the support of the group. Humans rely on both sight and touch to evoke memory but this rumination can also work to develop new understandings of past mistakes. Designed objects, although seemly inauthentic can work to change behaviour in the holder or at least induce a cognitive process. I imagined the men with the key in their pocket that they could reach for during times of stress.

The idea for the pattern of the first key came specifically from the word 'shift' which Boreham had identified in the facilitator focus group. A car shift diagram was a natural fit in terms of its metaphoric value as well as its connection to the idea of men and cars (this proved to be adequate later by a SVD focus group member who said he was a "petrol head" (figure 2). The concept for the key for the mentors was in response to adjectives for the word key (main, major, crucial etc) and the word mentor which led to 'protector' which led to 'manhole cover' 
(figure 3). The manhole cover protects without being visible, is both strong and secure as well as being inconspicuous. The keys with their associated pattern, produced by Giltech Precision Casting in Dunedin, were well received by the two SVD men in the focus group. They identified with the 'shift' key agreeing with the idea of sometimes being in reverse and also sometimes being idle! They also appreciated the mentor key stating that like mentors, you don't miss manhole covers until they are gone and that they can "stop you falling down a hole".

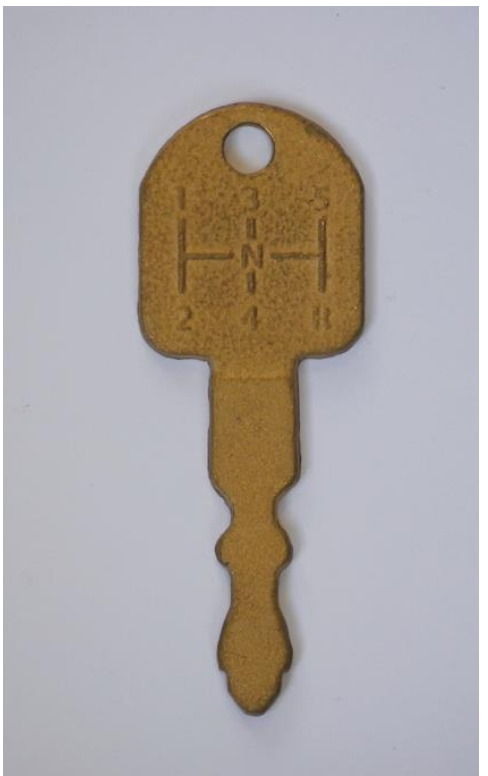

Figure 2 - Shift key (made by Giltech Precision Casting Dunedin

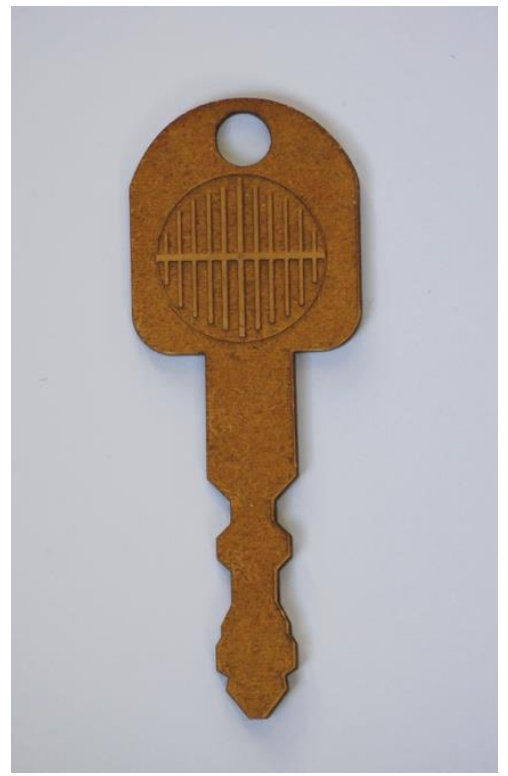

Figure 3 - Manhole Cover key (prototype MDF)

\section{Discussion}

This Masters project is currently in its final draft and undertaken while enrolled as a student at OP. In reference to the conference theme of value creation, my own journey involved developing the research question to fit with how the project evolved over time. The question changed from:

1) Can communication design help to change the narrative of domestic violence in Aotearoa New Zealand? To:

2) Using the designated term of champions at SVD (or those who have 'walked the walk'), how can their positive journey of change be reflected to new group members within a design context? To:

3) Can communication design support the transformation of violent male offenders within Stopping Violence Dunedin?

This project also aligned with Sustainable Development Goals (SVD), specifically Reduced Inequalities where the education and support for perpetrators of domestic violence ensures that women are kept safer. Design activist methodologies are a useful benchmark to provide a space for questioning assumptions around a community we often disregard, in this case perpetrators of domestic violence. Using practice-based and practice-led research allowed for my own educational exploration into the community that I had chosen to work with. In working 
to understand this community and their journey towards a possible transformation, I was able to create value for both the facilitators, by introducing milestones for the process as well as interpreting the milestones to construct a value object for the SVD men. The two-way exchange of the concept of value also tied in with the strength of manaakitaka at Otago Polytechnic and the values of sustainability and care that are embedded into our practice.

\section{Literature}

Baker, G. (2013). Effectively involving men in preventing violence against women. NZFVC Isues Paper, 5 November.

Boreham, C. (2018). Te ara o rongo The power to heal.

Campbell, L. (2012). Peer Support : Reframing the Journey From Lived Experience of Domestic Violence.

Grimaldi, Silvia; Fokkinga, Steven; Ocnarescu, I. (2013). Narratives In Design : A Study Of The Uses, Types, And Functions Of Narratives In Design Practice. DPPI '13: Proceedings of the 6th International Conference on Designing Pleasurable Products and Interfaces, 201-210. https://dl.acm.org/doi/10.1145/2513506.2513528

Hirsch, T. (2009). Learning from activists: lessons for designers. Interactions - Design Fiction, 16(3), 31. https://doi.org/10.1145/1516016.1516024

Lupton, E. (2017). Design is Storytelling. Cooper Hewitt, Smithsonian Design Museum.

MacDowell, E. L. (2013). Theorizing from particularity: Perpetrators and intersectional theory on domestic violence. The Journal of Gender, Race \& Justice, 16(2), 531-576.

Manning, Sean, Felton, Tanya-Maree, Boreham, Cinnamon, Ashdown, J. (2017). Increasing the Effectiveness of Stopping Violence Dunedin Programmes. July.

Pihama, L., Cameron, N., \& Nana, R. Te. (2019). New Zealand Family Violence Clearinghouse Historical trauma and whānau violence. October, 1-26. http://nzfvc.org.nz

Polaschek, D. L. L. (2016). Responding to Perpetrators of Family Violence. New Zealand Family Violence Clearinghouse (NZFVC) Issues Paper 11, 11. https://doi.org/10.1080/09627250008552887

Roguski, M., \& Gregory, N. (2014). Former Family Violent Perpetrators Narratives of Change.

Ruwhiu, L. A., Ashby, W., Erueti, H., \& Amokura Family Violence Prevention Consortium. (2009). A Mana Tane: Echo of Hope. Nzfvc.Org.Nz, 118. https://doi.org/TRO 362.8292 AMA Snegirev, M. (2017). A Relational Approach to Men's Non-Violence Groups.

Thorpe, A. (2011). Defining Design as Activism. Submitted to the Journal of Architectural Education. https://designactivism.net/wp-content/uploads/2011/05/Thorpedefiningdesignactivism.pdf 